\title{
Changing patterns of hospital admission for asthma, 1981-97
}

\author{
D S Morrison, P McLoone
}

\begin{abstract}
Background-Hospital admission rates for asthma have stopped rising in several countries. The aim of this study was to use linked hospital admission data to explore recent trends in asthma admissions in Scotland.

Methods-Linked Scottish Morbidity Records (SMR1) for asthma (ICD-9 493 and ICD-10 J45-6) from 1981 to 1997 were used to describe rates of first admissions and readmissions by age and sex. As a measure of resource use, annual trends in bed days used were also explored by age and sex.

Results-There were 160039 hospital admissions for asthma by 82421 individuals in Scotland during the study period. The overall hospital admission rate increased by $122 \%$ (from 106.7 to 236.7 per 100000 population) but this varied by sex, age, and admission type. First admissions rose by $70 \%$ from 73.2 per 100000 in 1986 to 124.8 per 100000 in 1997 while readmissions fell. Children ( $<15$ years) experienced a decline in overall admissions after 1992 due to falls in both new admissions and readmissions. By 1997 the ratio of female to male admissions was 0.57 in children, but 1.50 above 14 years of age. Mean lengths of stay fell from 10.7 days to 3.7 days between 1981 and 1997 and bed days used showed little change except for a decline after 1992 in children.

Conclusions-After a period of increasing hospitalisation for asthma in Scotland, rates of admission among children have begun to fall but among adults admissions continue to rise.

(Thorax 2001;56:687-690)
\end{abstract}

Keywords: asthma; hospital admission; readmission

MRC Social and Public Health Sciences Unit, 4 Lilybank Gardens, Glasgow G12 8RZ, UK

D S Morrison

P McLoone

Correspondence to: Dr D S Morrison david@msoc.mrc.gla.ac.uk

Received 27 October 2000 Returned to authors 15 January 2001 Revised version received 10 May 2001

Accepted for publication

1 June 2001 of severe asthma. Some insight into these components of care can be gained by separating first admissions and subsequent readmissions. In order to explore these components, linked hospital data are required. This allows individual histories rather than grouped episodes of care to be described. Studies that have used linked data have provided some evidence that readmissions have fallen at a similar rate to overall admissions. $^{5}$

In Scotland, NHS hospital data have been linked since $1981^{8}$ and these data present an opportunity to confirm whether trends reported in other countries have also occurred here. The Scottish linked data provide 100\% coverage of all NHS hospital admissions for a population of around 5 million people and include General Register Office (Scotland) death records. This linkage allows patterns of first admissions and readmissions to be distinguished. Using these data we carried out a retrospective descriptive study of asthma hospital admissions in Scotland between 1981 and 1997. The aim of the study was to describe trends in asthma admissions, separating trends in first admission and readmission. The data also allowed an investigation of resource use as measured by changes in bed days used per capita for the treatment of asthma.

\section{Methods}

All linked Scottish Morbidity Records (SMR1) for asthma (International Classification of Diseases 9th revision category 493 and 10th revision category J45-6) from the beginning of the linkage on 1 January 1981 until 31 December 1997 were obtained from the Information and Statistics Division of the Common Services Agency of the NHS in Scotland.

A patient's first admission for asthma during the period of the record linkage was labelled "first admission" and subsequent admissions as "readmissions". Age specific rates were estimated using the Registrar General Scotland mid year population estimates and were expressed as rates per 100000 population. When rates were calculated for all age groups they were age standardised to the European standard population. A 4 year lead in period was allowed before estimating first admission rates because it requires time to be able to distinguish true first admissions from readmissions. A 10 year comparison between first admission rates in 1985-7 and 1995-7 was made, together with a comparison of the proportion of new patients who were readmitted with asthma within 180 days of discharge. The comparison of readmission rates was made with the grouped years 1994-6 to allow 


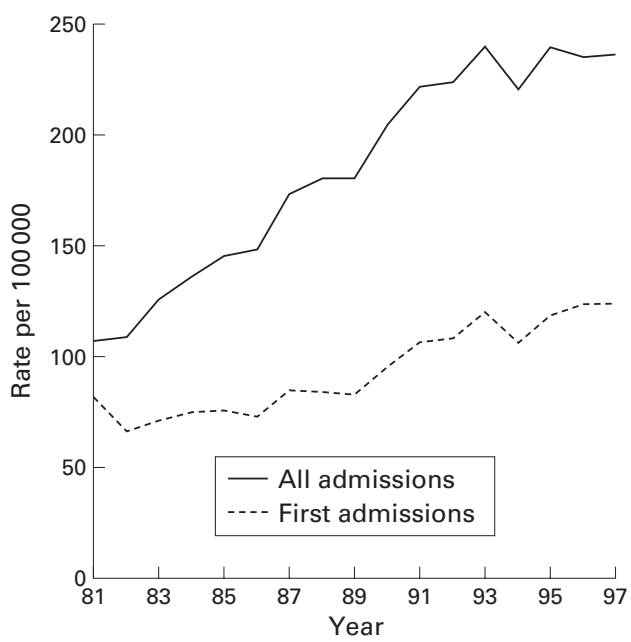

Figure 1 Trends in hospital asthma admissions (rate per 100000 population) showing all asthma admissions and first admissions for all ages and both sexes combined.

sufficient follow up of patients discharged towards the end of 1996. Trends in bed days used for the treatment of asthma during the period were examined for both sexes and the restricted age groups $0-14$ and $\geqslant 15$ years.

\section{Results}

TEMPORAL AND DEMOGRAPHIC TRENDS

Between 1981 and 1997 there were 160039 hospital admissions for asthma in Scotland. These admissions involved 82421 patients of whom $44 \%$ were under the age of 15 . Figure 1 shows that the overall age and sex standardised hospital admission rate increased by $122 \%$ from 106.7 to 236.7 per 100000 population during the entire period. A small fall in 1993 was then followed by a levelling of rates. Between 1986 and 1997, when the overall admission rate rose by $60 \%$, first admissions rose by $70 \%$ from 73.2 per 100000 in 1986 to 124.8 per 100000 . It follows that first admissions accounted for an increasing proportion of the overall rise compared with readmissions.

Females under the age of 15 were less likely than males to be admitted to hospital for asthma. Females aged 15 and over, however, were more commonly admitted. Between 1981 and 1997 the overall admission rate in females rose by $143 \%$ (from 103.9 to 252.6 per 100000 ) but, among males, it increased by only $101 \%$ (from 109.6 to 220.8 per 100000 ). As a result, the overall ratio of female to male admissions increased from 0.95 to 1.14 . At ages below 15 the female to male ratio changed only slightly from 0.53 to 0.57 , but in patients aged 15 and over the ratio increased from 1.23 to 1.50 .

Figures 2 and 3 show that admission rates for both sexes increased for all age groups but that the magnitude and pattern of change varied. The figures show that, for each sex, the largest increase in asthma admissions occurred at ages 0-39 until 1992. After 1992 admission rates at ages $0-14$ began to fall. In contrast, admissions at ages 15 and over continued to rise after 1992 with the largest increase occurring at ages

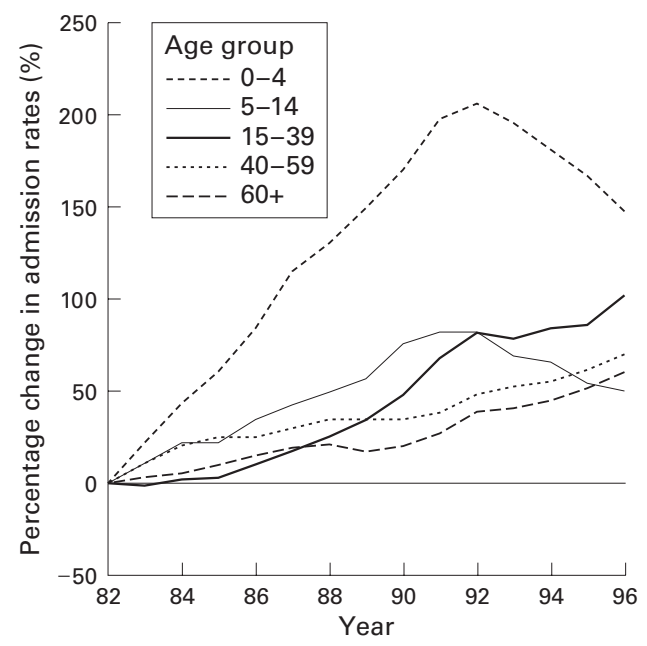

Figure 2 Percentage change in age specific hospital admission rates in men in successive years between 1981 and 1997 compared with baseline value of age specific rate during 1981-3. Rates are grouped as three point moving averages.

15-39. There was a suggestion of a slowing down in the increase among men aged 15-39, but not among women. By the end of 1997 admissions among women aged 15-39 had increased by $196 \%$. When trends in first admissions were examined, patterns similar to those seen for all admissions emerged.

Approximately $50 \%$ of all asthma admissions are first admissions for asthma. Table 1 shows that the percentage of first time admissions was highest at ages $0-4$ and 60 and over. This proportion increased during the period among those aged 0-4 and decreased slightly among those aged 60 and over. Apart from these ages, the proportion of first time admissions did not appear to change significantly over time or show systematic variation by age. There was, however, a suggestion that the proportion of first time admissions was slightly lower in women than in men. Examination of repeat admission rates reinforced this observation. Readmission rates within 180 days of discharge

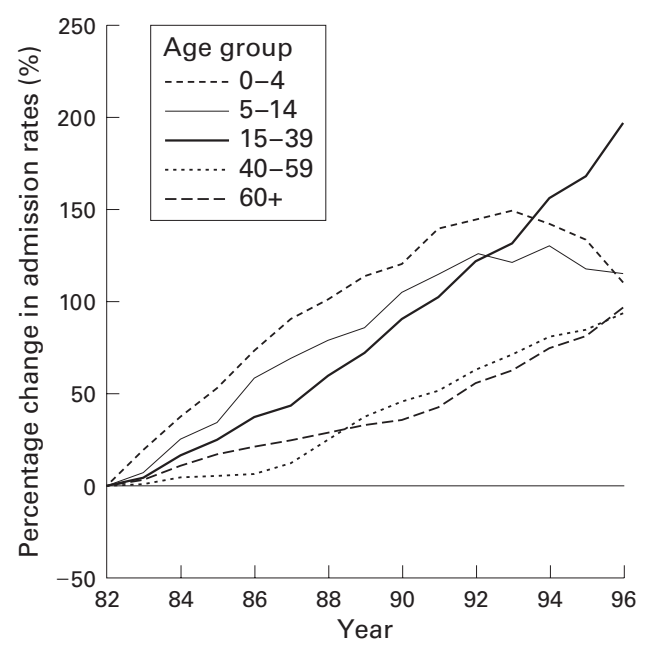

Figure 3 Percentage change in age specific hospital admission rates in women in successive years between 1981 and 1997 compared with baseline value of age specific rate during 1981-3. Rates are grouped as three point moving averages 
Table 1 Age and sex specific admission rates (per 100000 population) for first admissions in two time periods 1985-7 and 1995-7 with percentage of first admission patients who are readmitted within 180 days of discharge in 1985-7 and 1994-6

\begin{tabular}{|c|c|c|c|c|c|c|c|}
\hline & \multirow[b]{3}{*}{ Age } & \multicolumn{3}{|c|}{$\begin{array}{l}\text { First admissions (rates per } 100000 \text { and \% of all asthma } \\
\text { admissions) }\end{array}$} & \multicolumn{3}{|c|}{ Readmission within 180 days (number of readmissions) } \\
\hline & & \multirow{2}{*}{$\begin{array}{l}\text { 1985-7 } \\
\text { Rate (\%) }\end{array}$} & \multicolumn{2}{|l|}{$1995-7$} & \multirow{2}{*}{$\frac{1985-7}{\%(n)}$} & \multirow{2}{*}{$\frac{1994-6}{\%(n)}$} & \multirow[b]{2}{*}{ Change $(95 \% \mathrm{CI})$} \\
\hline & & & Rate (\%) & $\%$ change $(95 \% \mathrm{CI})$ & & & \\
\hline \multirow[t]{5}{*}{ Men } & $0-4$ & $430(52)$ & $687(62)$ & $60(54$ to 65$)$ & $25.1(535)$ & $18.3(641)$ & $-6.8(-9.1$ to -4.6$)$ \\
\hline & $5-14$ & $133(46)$ & $150(47)$ & $13(7$ to 19$)$ & $9.1(122)$ & $6.1(91)$ & $-3.0(-5.0$ to -1.0$)$ \\
\hline & $15-39$ & $33(50)$ & $60(49)$ & $81(72$ to 89$)$ & $8.8(88)$ & $5.4(80)$ & $-3.4(-5.5$ to -1.3$)$ \\
\hline & $40-59$ & $46(49)$ & $63(48)$ & $37(29$ to 44$)$ & $12.7(99)$ & $9.2(100)$ & $-3.5(-6.4$ to -0.6$)$ \\
\hline & $60+$ & $79(65)$ & $101(60)$ & $28(20$ to 34$)$ & $9.3(91)$ & $9.0(112)$ & $-0.3(-2.7$ to 2.1$)$ \\
\hline \multirow[t]{5}{*}{ Women } & $0-4$ & $228(48)$ & $354(63)$ & 55 (48 to 63$)$ & $28.9(312)$ & $19.4(346)$ & $-9.5(-12.7$ to -6.2$)$ \\
\hline & $5-14$ & $78(45)$ & $102(43)$ & $31(22$ to 38$)$ & $10.5(79)$ & $7.3(72)$ & $-3.2(-6.0$ to -0.6$)$ \\
\hline & $15-39$ & $53(48)$ & $116(48)$ & $119(112$ to 127$)$ & $9.6(148)$ & $8.8(239)$ & $-0.8(-2.6$ to 1.1$)$ \\
\hline & $40-59$ & $56(47)$ & $99(45)$ & $77(68$ to 84$)$ & $11.9(121)$ & $8.8(152)$ & $-3.2(-5.6$ to -0.8$)$ \\
\hline & $60+$ & $78(59)$ & $118(54)$ & 51 (44 to 57$)$ & $10.6(153)$ & $9.1(180)$ & $-1.6(-3.6$ to 0.5$)$ \\
\hline
\end{tabular}

from hospital were higher among those aged 0-4 and, with a few exceptions, rates were slightly higher among women. Between the two time periods readmission rates fell in both sexes across all age groups, with the greatest decline occurring in patients aged $0-4$ years.

LENGTH OF STAY AND BED DAYS USED

The resource implications of the changing pattern of asthma admissions, in terms of bed days used for the condition, have been tempered by an approximate decline of two thirds in the overall mean length of stay, declining from 10.7 days in 1981 to 3.7 days in 1997. The mean length of stay was slightly longer in women than in men, but this was mainly a feature among those aged 50 and over. Figure 4 shows the overall bed days used by men and women at ages $0-14$ and $\geqslant 15$ years. At ages $0-14$ bed days used by males were higher than those used by females, reflecting higher admission rates among males in this age group. In terms of resources used at these ages, they have been declining steadily since about 1992 . Figure 4 also shows the bed days used for those patients aged $\geqslant 15$ years. For this age group the difference between men and women partly reflects the greater admission rates among women and the longer length of stay that they experience. At these ages there has been no clear change in the bed days used by men and women, although there is a suggestion of a slight fall among men and an increase among women after 1986. In contrast, bed days used by those in the younger age groups increased rapidly during the 1980 s and then fell after 1992.

\section{Discussion}

The levelling and declining patterns of hospital admissions for asthma found elsewhere in the late 1980 s and early $1990 \mathrm{~s}^{5-7}$ also occurred in children but not in adults in Scotland. Hospital admissions for asthma in Scotland rose sharply throughout the 1980s, more than doubling between 1981 and 1991, but in the early 1990s admissions levelled off. Both phenomena were strongly influenced by rates of admissions in children (0-14 years) which rose sharply until 1992 and then fell. In adults ( $\geqslant 15$ years) admissions continued to climb through the 1990s.

First admissions rose throughout the 1980 s and 1990s at all ages and in both sexes, while

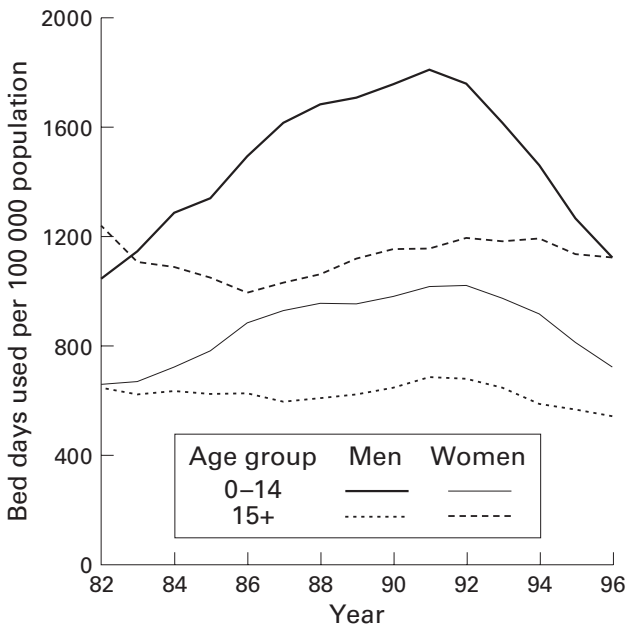

Figure 4 Trends in bed days used (per 100000 population) in men and women aged $0-14$ and $15+$ years.

readmissions fell. In children first admission rates also fell after 1992 and together these trends led to a decline in overall admissions. While readmissions fell in adults, this did not reverse the dominant effect of rising first admissions on overall admission rates. A decline in readmission rates has been observed previously, ${ }^{29}$ but in the context of increasing admissions in children. It is tempting to ascribe the rise in first admissions to increasing prevalence of asthma, ${ }^{10}$ the fall among children to changes in admission thresholds in paediatric hospitals, ${ }^{11}$ and the fall in readmissions to better initial treatment or follow up by hospitals. Testing these hypotheses is beyond the scope of our data and would require further research using measures of clinical practice and case severity. The differential patterns of first and subsequent admissions does suggest that there are likely to be more complex explanations to these trends than that they are simply a reflection of the overall increase in acute hospital admissions. ${ }^{12}$

These results confirm previous findings that boys are almost twice as commonly admitted to hospital for asthma than girls, ${ }^{1}$ while women are more commonly admitted than men. ${ }^{34}$ Paradoxically, the reported prevalence of asthma is higher in men. ${ }^{13}$ We are not aware of evidence to suggest that the severity of asthma differs with age between males and females. 
There are important health service planning implications of changing hospital admission rates for asthma. Trends in bed days used for asthma in children have followed similar patterns to overall admissions, with an increase until 1992 followed by a fall. There has been no clear increase in bed days used for asthma in adults in Scotland, despite the increase in admissions.

Hospital data represent only the most severe minority of cases who have been filtered through self-management, primary care, and hospital admission criteria. The SMR1 data do not contain information on severity or case complexity, so changes in hospital thresholds for admission or in patterns of presentation cannot be described. However, the linked SMR1 data ${ }^{8}$ have a number of strengths. They describe actual resources used for asthma and indicate demographic and socioeconomic effects. They provide national $100 \%$ coverage of inpatient care of individual patients in Scotland since 1981 and are therefore uniquely comprehensive. However, as with any routinely coded data, they depend on the accuracy of coding diagnoses from case notes and at any stage of transcription they could be subject to errors.

In conclusion, the increase in hospital admissions for asthma, which has been a feature of the condition for several decades, is changing. Admissions have stopped rising in Scotland since 1992 due largely to a fall in childhood admissions. First admissions rose then fell among children but not among adults. Readmissions have fallen at all ages but in children the fall in readmissions has contributed to the net decline since 1992. Lengths of stay have fallen by about two thirds so that there has been little change in bed days used for asthma except in children, among whom the fall in bed days used has mirrored the decline in admissions since 1992 .

Both authors are funded by the Chief Scientist Office of the Scottish Executive Health Department (CSO) but the views expressed in this paper are not necessarily those of the CSO. The authors have no conflicts of interest to declare.

1 Alderson M. Trends in morbidity and mortality and asthma. Population Trends 1987;49:18-23.

2 Anderson HR. Increase in hospital admissions for childhood asthma: trends in referral, severity, and readmissions from 1970 to 1985 in a health region of the United Kingdom. Thorax 1989;44:614-9.

3 Hyndman SJ, Williams DRR, Merrill SL, et al. Rates of admission to hospital for asthma. BMF 1994;308:1596600 .

4 Harju T, Keistinen T, Tuuponen $\mathrm{T}$, et al. Hospital admissions of asthmatics by age and sex. Allergy 1996;51: 63-6.

5 To T, Dick P, Feldman W, et al. A cohort study on childhood asthma admissions and readmissions. Pediatrics 1996;98: $191-5$.

6 Kemp T, Pearce N. The decline in asthma hospitalisations in persons aged 0-34 years in New Zealand. Aust NZ F Med 1997;27:578-81.

7 Wever-Hess J, Wever AMJ. Asthma statistics in the Netherlands 1980-94. Respir Med 1997;91:417-22.

8 Kendrick S, Clarke J. The Scottish record linkage system. Health Bull (Edinb) 1993;51:72-9.

9 Senthilselvan A. Effect of readmissions on increasing hospital admissions for asthma in children. Thorax 1995:50:9346.

10 Magnus P, Jaakkola JJ. Secular trend in the occurrence of asthma among children and young adults: critical appraisal
of repeated cross sectional surveys. BMF 1997;314:1795-9.

11 Russo MJ, McConnochie KM, McBride JT, et al. Increase in admission threshold explains stable asthma hospitalization admission threshold explains stable
rates. Pediatrics 1999;104:454-62.

12 Kendrick $S$. The pattern of increase in emergency hospital admissions in Scotland. Health Bull (Edinb) 1996;54:16983

13 Fleming DM, Crombie DL. Prevalence of asthma and hay fever in England and Wales. BMF 1987;294:279-83.

\title{
Narrative Based Medicine, An Interdisciplinary Conference
}

\author{
Research, Narrative, and Practice
}

A two day conference-Monday 3rd and Tuesday 4th September 2001

Homerton College, Cambridge, UK

BMF Publishing Group

For full details contact: BMA/BMJ Conference Unit, Tavistock Square, London, WC1H 9JP Tel: +44 (0)20 7383 6819; fax: +44 (0)20 7383 6663; email: clyders@bma.org.uk. www.quality.bmjpg.com 